\title{
Technical note: Boundary layer height determination from lidar for improving air pollution episode modeling: development of new algorithm and evaluation
}

\author{
Ting Yang ${ }^{1}$, Zifa Wang ${ }^{1}$, Wei Zhang ${ }^{2}$, Alex Gbaguidi ${ }^{1}$, Nobuo Sugimoto ${ }^{3}$, Xiquan Wang ${ }^{1}$, Ichiro Matsui ${ }^{3}$, and \\ Yele Sun ${ }^{1}$ \\ ${ }^{1}$ State Key Laboratory of Atmospheric Boundary Layer Physics and Atmospheric Chemistry, Institute of \\ Atmospheric Physics, Chinese Academy of Sciences, Beijing 100029, China \\ ${ }^{2}$ Aviation Meteorological Center of China, Beijing 100021, China \\ ${ }^{3}$ National Institute for Environmental Studies, 16-2 Onogawa, Tsukuba, 305-8506, Japan
}

Correspondence to: Ting Yang (tingyang@mail.iap.ac.cn) and Zifa Wang (zifawang@mail.iap.ac.cn)

Received: 12 November 2016 - Discussion started: 3 January 2017

Revised: 7 April 2017 - Accepted: 14 April 2017 - Published: 22 May 2017

\begin{abstract}
Predicting air pollution events in the low atmosphere over megacities requires a thorough understanding of the tropospheric dynamics and chemical processes, involving, notably, continuous and accurate determination of the boundary layer height (BLH). Through intensive observations experimented over Beijing (China) and an exhaustive evaluation of existing algorithms applied to the BLH determination, persistent critical limitations are noticed, in particular during polluted episodes. Basically, under weak thermal convection with high aerosol loading, none of the retrieval algorithms is able to fully capture the diurnal cycle of the BLH due to insufficient vertical mixing of pollutants in the boundary layer associated with the impact of gravity waves on the tropospheric structure. Consequently, a new approach based on gravity wave theory (the cubic root gradient method: CRGM) is developed to overcome such weakness and accurately reproduce the fluctuations of the BLH under various atmospheric pollution conditions. Comprehensive evaluation of CRGM highlights its high performance in determining BLH from lidar. In comparison with the existing retrieval algorithms, CRGM potentially reduces related computational uncertainties and errors from BLH determination (strong increase of correlation coefficient from 0.44 to 0.91 and significant decreases of the root mean square error from 643 to $142 \mathrm{~m}$ ). Such a newly developed technique is undoubtedly expected to contribute to improving the accuracy of air quality modeling and forecasting systems.
\end{abstract}

\section{Introduction}

The boundary layer height (BLH) illustrates the relationships between air pollution intensity, duration, and scope; it constitutes an important factor influencing the diffusion of pollutants in the low atmosphere (Tie et al., 2007; Quan et al., 2013). An increase of air pollutants is often associated with a shallow BLH, while a decrease of pollutants is accompanied by obvious uplift of the BLH. Besides the physical effects, BLH can also affect the precursor particles' concentration and distribution, which might affect the chemical transformation of fine particulate matter (Ansari and Pandis, 1998). BLH is also a key parameter for air pollution models; it determines the volume available for the dispersion of pollutants and is involved in many predictive and diagnostic methods and/or models that assess pollutant concentrations (Seibert et al., 2000). The bias of the BLH between the air quality model and observation is a potential cause of model's difficulties to accurately forecast air pollution episodes (Dabberdt et al., 2004). Therefore, accurately acquiring the BLH, especially during polluted episodes, is of great significance to investigating air pollution issues.

Many techniques have been developed to determine the $\mathrm{BLH}$, for example, through radiosonde measurements (Stull, 1988), remote sensing (Emeis et al., 2007), laboratory experiments (Park et al., 2001), and model simulations (Dandou et al., 2009). The high spatiotemporal resolutions make aerosol lidar techniques (light detection and ranging) one of the most 
suitable systems for analyzing the boundary layer structure and determining the BLH (Flamant et al., 1997). Due to the complex vertical structure of boundary layer, numerous methods have been proposed to accurately retrieve the BLH from lidar, such as the maximum variance method (Hooper and Eloranta, 1986), fitting idealized profile method (Steyn et al., 1999), first point method (Boers and Melfi, 1987), threshold method (Dupont et al., 1994), wavelet transform method (Davis et al., 2000; Baars et al., 2008), first gradient method (Flamant et al., 1997), logarithm gradient method (Senff et al., 1996), and normalized gradient method (He et al., 2006). However, so far most of the algorithms have been tested and validated only over relatively unperturbed homogeneous terrain, for example, oceans (Melfi et al., 1985; Flamant et al., 1997), rural areas, and clean meteorological conditions (Piironen and Eloranta, 1995). Limited evaluations of the algorithms have been carried out in polluted megacities in developing countries, associated with a high density of buildings and heavy anthropogenic pollutants. Nevertheless, the surface roughness and high aerosol loading in the boundary layer result in a more complex structure and increase the difficulty of BLH retrieval based on these algorithms.

As one of the largest megacities in Asia affected by heavy pollution, Beijing provides a particular challenge to resolving the BLH determination. Specifically, the movement of the atmosphere can affect the distribution of pollutant concentrations; moreover, vertically propagating gravity waves influence the structure of the atmosphere and cause some of the spatiotemporal variability (Fritts and Alexander, 2003). Gravity waves thus provide new theoretical insights for the development of a new algorithm in determining BLH by taking into account a probably insufficient vertical mixing of pollutants under weak thermal convection and pollutant accumulation at high altitudes due to long-range transport processes. Beijing, often governed by stagnant meteorological conditions, is surrounded by mountains to the west, north, and northeast, and characterized by favorable conditions to generate and maintain gravity waves. Such specific atmospheric conditions provide the opportunity to obtain insights into the difficulties related to the BLH retrieval based on existing algorithms and to evaluate the performance of a new approach that considers the impact of gravity waves. Based on an intensive observation campaign over Beijing, this paper aims at delving into the limitations of current retrieval algorithms employed for BLH determination from lidar during a polluted period and at coming up with the development of a new algorithm compatible with all atmospheric pollution conditions. This work therefore provides, for the first time, a prototype of how to integrate into the BLH retrieval process gravity waves and the resulting complexity of the low-troposphere structure under conditions of heavy aerosol loading. Section 2 presents a detailed description of the lidar observational experiment setting over Beijing and discusses the limitations of current algorithms for BLH retrieval; Sect. 3 discusses the development of a new algo- rithm; Sect. 4 presents the comprehensive evaluation of the new retrieval algorithm and comparative analysis with existing methods; and conclusion and environmental implications are given in Sect. 5 .

\section{Lidar experiment setting over Beijing and evaluation of existing BLH retrieval algorithms}

\subsection{Lidar observation campaign}

Beijing, the capital of China, is located at $39^{\circ} 56^{\prime} \mathrm{N}$, $116^{\circ} 20^{\prime} \mathrm{E}$ on the northwest border of the great North China Plain. It is surrounded by the Yan Mountains to the west, north, and northeast. The topography favors accumulation of pollutants. The air pollution is critically high, with the peak concentration of $\mathrm{PM}_{2.5}$ exceeding $500 \mu \mathrm{g} \mathrm{m}^{-3}$ (Sun et al., 2014). An intensive observation campaign was conducted from 1 July to 16 September 2008 at the Institute of Atmospheric Physics (IAP), Chinese Academy of Sciences $\left(39^{\circ} 58^{\prime} 28^{\prime \prime} \mathrm{N}, 116^{\circ} 22^{\prime} 16^{\prime \prime} \mathrm{E}\right)$, located between the north third and fourth ring roads in Beijing and considered as a highly polluted urban site. A dual-wavelength (1064, $532 \mathrm{~nm}$ ) depolarization lidar developed by the National Institute for Environmental Studies, Japan, sits on the rooftop of a $28 \mathrm{~m}$ high building. The lidar is used to retrieve the $6 \mathrm{~m}$ space-resolved and $10 \mathrm{~s}$ time-resolved aerosol vertical structure, but only for altitudes $>100 \mathrm{~m}$ due to an incomplete overlap between the field of telescope view and the laser beam. More details of the lidar parameters can be found in the research of Sugimoto et al. (2002) and Yang et al. (2010). $\mathrm{PM}_{2.5}$ sampling was continuously conducted near the lidar site. Potential temperature and relative humidity observed by radiosonde are integrated into the classic methods to retrieve the BLH and are employed to evaluate new algorithms (Stull, 1988).

An unprecedented 78-day intensive radiosonde campaign was conducted over the Institute of Atmospheric Physics site (four times per day: 02:00, 08:00, 14:00, and 20:00 local standard time) in line with the lidar campaign at a radiosonde observatory located in southern Beijing $\left(39^{\circ} 48^{\prime} \mathrm{N}\right.$, $116^{\circ} 28^{\prime} \mathrm{E}$ ). Daily $\mathrm{PM}_{2.5}$ concentrations observed over the Institute of Atmospheric Physics site between July and September 2008 are shown in Fig. 1. A typical extended polluted episode occurred between 24 and 27 July, when the $\mathrm{PM}_{2.5}$ concentration exceeded the Grade III National Ambient Air Quality Standards (moderate pollution, GB3095$2012,115 \mu \mathrm{g} \mathrm{m}^{-3}, 24 \mathrm{~h}$ average). The beginning and end of the pollution episode were on 24 and 28 July, respectively, while 27 July was the heaviest pollution day during the campaign, with a $\mathrm{PM}_{2.5}$ concentration of $195 \mu \mathrm{g} \mathrm{m}^{-3}$. On $27 \mathrm{July}$, the southeastern edge of a low-pressure system of northern China prevailed over Beijing, inducing southerly flows. Under such meteorological conditions, accumulation of pollutants (due to long-range transport from neighboring regions) 


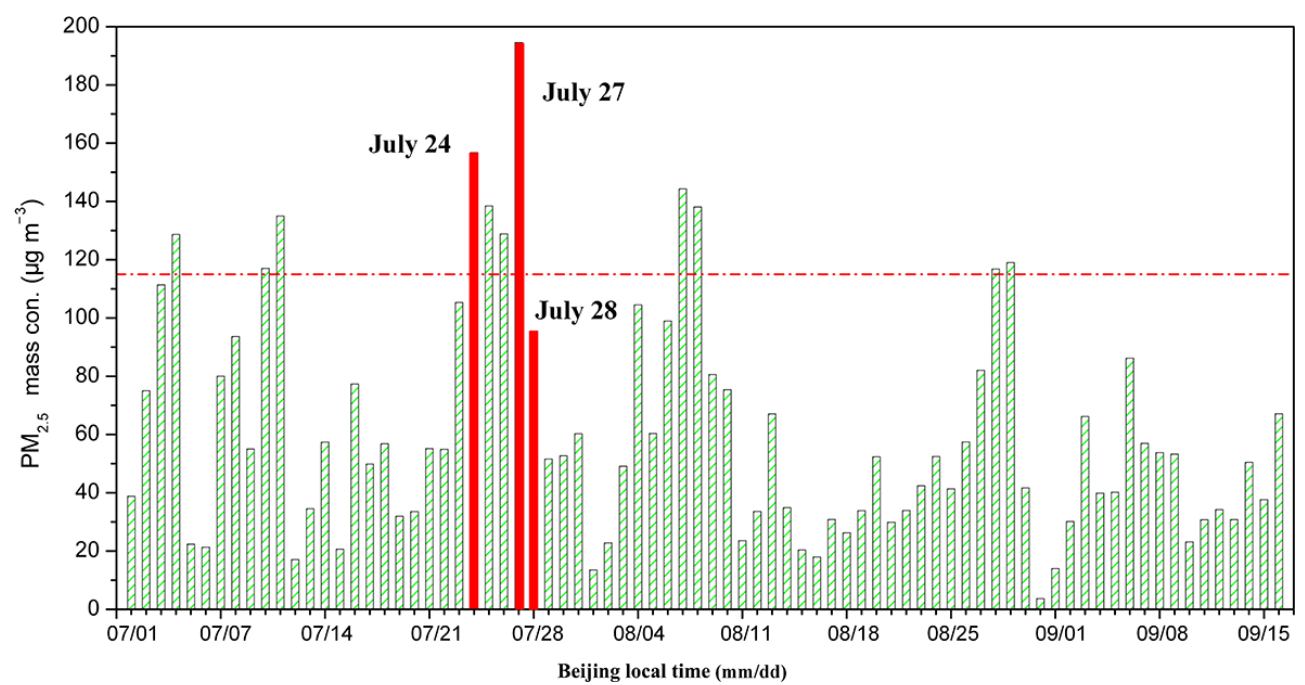

Figure 1. Daily variation of the $\mathrm{PM}_{2.5}$ concentration between July and September 2008 at IAP. The dotted line represents the definition of a moderate pollution day $\left(\mathrm{PM}_{2.5}=115 \mu \mathrm{g} \mathrm{m}^{-3}\right)$, and 24,27 and 28 July are highlighted.

occurs over the southern area (Chan and Yao, 2008). Below $850 \mathrm{hPa}$, warm advection over northern China triggers a significant increase of air temperature at low altitudes, preventing the vertical diffusion of pollutants (Fig. S1 in the Supplement). This presents a typical condition for evaluating the performance of existing retrieval algorithms in determining the BLH.

\subsection{Existing gradient algorithm for BLH determination}

In normal conditions of an aerosol-laden boundary layer and clean overlying free atmosphere, the gradient of the rangesquared-corrected signal (RSCS) exhibits a strong negative peak at the transition between the boundary layer and free atmosphere. Based on this principle, gradient algorithms were proposed and had become the most widely used ones. In this paper, we focus on the three most popular gradient methods, including the first gradient method (GM), first logarithm gradient method (LGM), and first normalized gradient method (NGM). The optical power measured by lidar is proportional to the signal backscattered of particles and molecules present in the atmosphere. The lidar signal can be expressed by Eq. (1) below:

$\mathrm{RS}(\lambda, r)=\frac{C}{r^{2}} E_{0}\left[\beta_{\mathrm{m}}(\lambda, r)+\beta_{\mathrm{p}}(\lambda, r)\right] T^{2}(\lambda, r)+\mathrm{RS}_{0}$,

where $\beta_{\mathrm{p}}(\lambda, r)$ and $\beta_{\mathrm{m}}(\lambda, r)$ are the particular and molecular backscatter coefficients, respectively; $C$ is a constant for a given lidar system; $E_{0}$ is the laser output energy; $T^{2}$ is the atmospheric transmission; $r$ is the range between the laser source and the target; $\lambda$ is the wavelength; and $\mathrm{RS}_{0}$ is the background signal.

The RSCS is then defined in Eq. (2) by

$\mathrm{RSCS}=\left(\mathrm{RS}-\mathrm{RS}_{0}\right) r^{2}$.
The first GM, which assimilates the BLH to the altitude $\left(h_{\mathrm{GM}}\right)$ of the minimum gradient of the RSCS (Flamant et al., 1997; Hayden et al., 1997), is obtained by

$h_{\mathrm{GM}}=\min \left[\frac{\partial \mathrm{RSCS}}{\partial r}\right]$.

The first LGM determines the BLH at the altitude, $h_{\mathrm{LGM}}$, where the minimum of the first gradient of RSCS logarithm is reached (Senff et al., 1996). This altitude is calculated by the equation

$h_{\mathrm{LGM}}=\min \left[\frac{\partial \ln (\mathrm{RSCS})}{\partial r}\right]$.

The first NGM, described below, estimates the BLH at the altitude where the normalized RSCS gradient reaches a minimum (He et al., 2006).

$h_{\mathrm{NGM}}=\min \left[\frac{\partial \mathrm{RSCS}}{\partial r \times \mathrm{RSCS}}\right]$

\subsection{Evaluation of existing algorithms' performance during a polluted period}

As a key parameter for air pollution forecasting models, BLH can determine the volume available for the dispersion of pollutants (Seibert et al., 2000). Accurate retrieval of the BLH by automatic algorithms not only allows making insights into its diurnal fluctuations during pollution episodes, but it also contributes to validating modeling results and improving prediction performance.

Prior to the calculation of the gradient with the current three BLH retrieval algorithms, a moving average of $30 \mathrm{~m}$ 


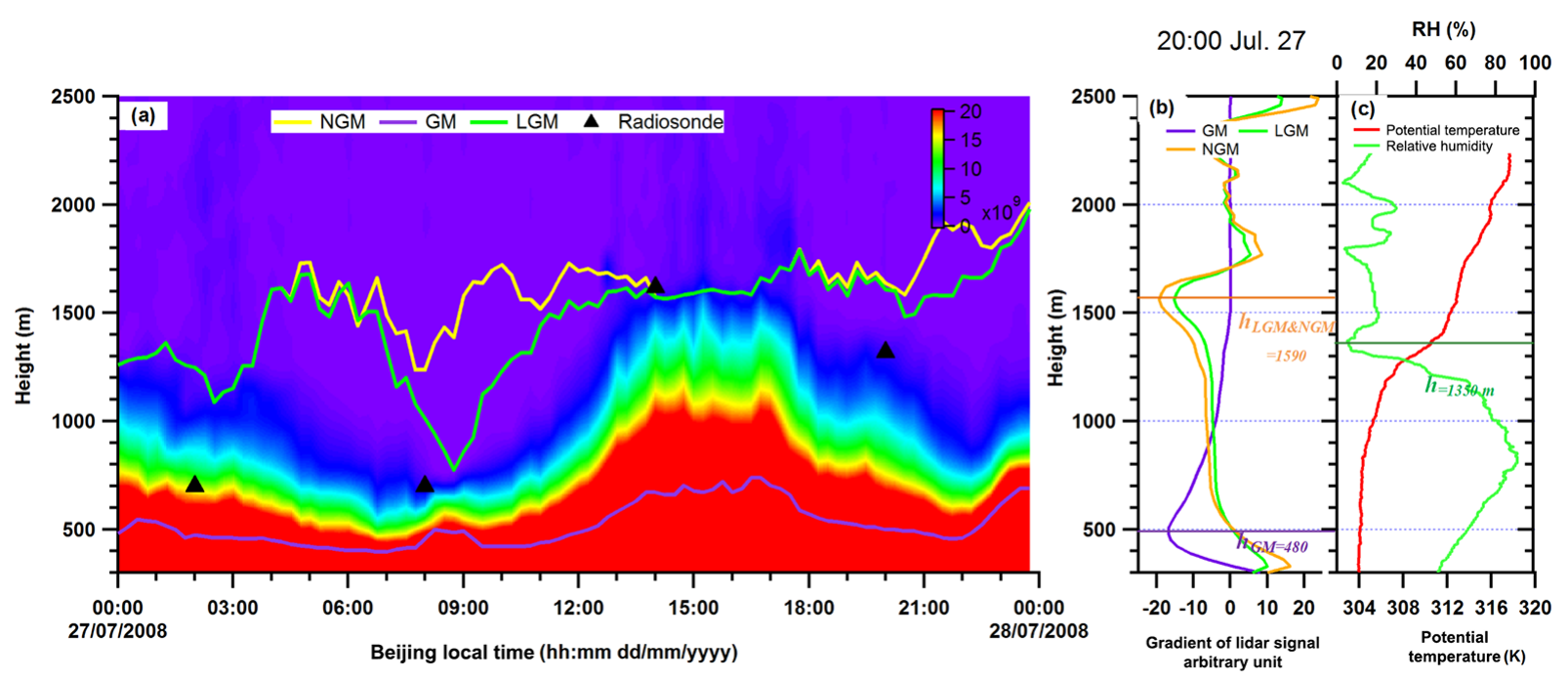

Figure 2. (a) Evolution of the lidar range-squared-corrected signal (RSCS) at $532 \mathrm{~nm}$ on $27 \mathrm{July}$. The color scale indicates the intensity of the RSCS, and warm colors represent stronger light scattering. The diurnal BLH retrieved by LGM, GM, and NGM are illustrated as green, purple, and yellow lines, respectively. Black triangles show the BLH retrieved by radiosonde. (b) The profiles of LGM, GM, and NGM, and the corresponding retrieval BLH at 20:00 on 27 July. LGM, GM, and NGM are illustrated as green, purple, and yellow lines, respectively. (c) Potential temperature and relative humidity at 20:00 on 27 July.

in height was assumed in the stored lidar profiles in accordance with the study of Pal et al. (2010), who previously reported that a height difference of $30 \mathrm{~m}$ was the most appropriate for identifying the minimum of the gradient. Typical gradient profiles of the RSCS and retrieved BLH from various algorithms with corresponding radiosonde profiles of the potential temperature and relative humidity are illustrated in Fig. $2 b$ and c. Strong negative peaks were detected in the profiles for each algorithm to define the BLH (Fig. 2b). As illustrated in Fig. 2b, at 20:00 on 27 July, the BLH retrieved by GM is $480 \mathrm{~m}$ versus about $1590 \mathrm{~m}$ retrieved by LGM and NGM. Determining the BLH from radiosonde measurements based on the potential temperature sharply increasing with altitude and decreasing relative humidity is the classic and most accurate approach usually applied to evaluate lidar retrieval results (Seibert et al., 2000). At 20:00 on 27 July, the radiosonde identified a region at $1350 \mathrm{~m}$, considered as the actual BLH (Fig. 2c). Thus, GM significantly underestimated the BLH by approximately $870 \mathrm{~m}$, while LGM and NGM overestimated the BLH by about $240 \mathrm{~m}$. The diurnal cycle of the BLH retrieved by these algorithms is illustrated in Fig. 2a in comparison with the four radiosonde measurements (02:00, 08:00, 14:00, 20:00). The results demonstrated that none of the algorithms was able to fully capture the diurnal cycle of the BLH. The average underestimation was 500$600 \mathrm{~m}$ for the GM algorithm (strongly supporting previous findings of $\mathrm{He}$ et al., 2006), as opposed to an overestimation of 400-500 m for the LGM and NGM algorithms on 27 July, in agreement with the profile analyses (Fig. 2b). In addition, the performance of the retrieval algorithms on 24 and 28 July (Figs. S2 and S3) strongly correlated with that found on 27
July. This highlights the critical bias and limitations of these algorithms in accurately determining the BLH under heavy aerosol loading.

\subsection{Limitation analysis}

The top of the boundary layer is often associated with strong gradients in the aerosol content, so a simple negative gradient peak seems suitable to determine the BLH. However, data interpretation from aerosol lidar is often not straightforward. Aerosol loading in the low troposphere mainly originates from the ground level. Thus, under stable conditions, large negative gradient peaks possibly exist near ground level (even larger than that of the BLH) due to insufficient vertical mixing of the pollutants in the boundary layer. Thus, the BLH might be wrongly determined by the GM based on these negative gradient peaks with critical underestimation. On the other hand, both LGM and NGM originally developed to filter out the influence of aerosols near the surface and to improve the original GM (Sicard et al., 2006; Emeis et al., 2007) result in an overestimation of the BLH. LGM is normally supposed to filter out the negative gradient peak near the ground to a certain extent, producing a higher BLH than GM (He et al., 2006). Such overestimation is probably induced by accumulation of aerosol at higher altitude due to adventive chemical transport (Stettler and HoyningenHuene, 1996), undetectable by the retrieval algorithms due to the impact of gravity waves on the atmosphere structure (Gardner, 1996), which inhibits the filtration skills of LGM and NGM. It is clear that the accuracy of current retrieval algorithms in determining the BLH from lidar is limited by 


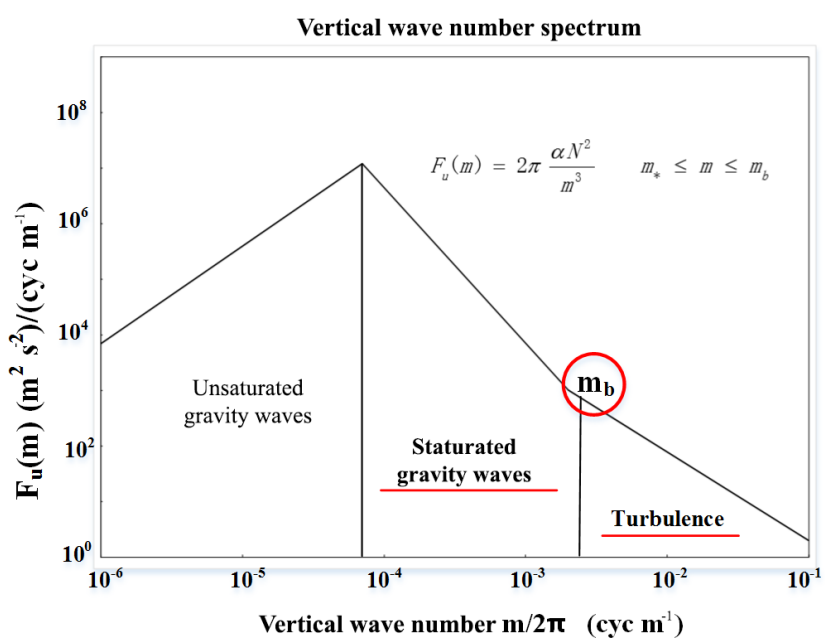

Figure 3. The canonical gravity wave vertical wave number spectrum of horizontal wind fluctuations. From J. Atmos. Terr. Phys., 58, 1577, 1996.

conditions of heavy aerosol loading (with insufficient vertical mixing in the boundary layer) associated with the impact of vertically propagating gravity waves.

\section{Development of a new algorithm}

\subsection{Rationale and scientific basis}

As evoked in previous sections, heavy pollution and propagation of gravity waves critically limit the accuracy of current retrieval algorithms in determining the BLH from lidar. Beijing is characterized by favorable conditions to generate and maintain gravity waves in particular due to the presence of Qinghai-Tibet Plateau in the west, which is considered as a potential source of gravity waves in Beijing (Gong et al., 2013). In fact, during a campaign of more than 2 years (from April 2010 to September 2011), daily and seasonal vertical mixing of wavelengths and phase velocities of 162 quasimonochromatic gravity waves were observed over Beijing from lidar (Gong et al., 2013). Moreover, statistical analysis of the captioned campaign revealed that gravity waves were maximal in summer (June-August), corresponding practically to the discussed observation period of the present study (1 July-16 September). It is clear that this finding serves as potential observational evidence of gravity wave and strong support of the present study. According to the research of the Global Atmospheric Sampling Program, the gravity waves generated by the mountains are $\sim 2-3$ times higher than those generated by plains and oceans and $\sim 5$ times higher than those from other sources (Fritts and Alexander, 2003). Heavy air pollution episodes frequently occur in Beijing with stagnant meteorological conditions that maintain the gravity waves (Gibert et al., 2011).
The linear instability theory (LIT) of gravity waves (Dewan and Good, 1986) is illustrated in Fig. 3. $m_{\mathrm{b}}$ (buoyancy wave number) makes the transition between waves and turbulence (Gardner, 1996). Under $m>m_{\mathrm{b}}$ conditions, wind fluctuations are dominated by turbulence, while under $m<m_{\mathrm{b}}$ conditions, the fluctuations are governed by waves. The upper boundary layer is the transition between the boundary layer (where turbulence is the predominant process) and the free atmosphere (where large-scale waves can propagate vertically). The BLH is associated with $m_{\mathrm{b}}$ to some extent. According to the research of Gardner et al. (1996), $F_{u}\left(m_{\mathrm{b}}\right)$ (the spectrum of horizontal wind fluctuations) is proportional to $m_{\mathrm{b}}^{-3}$ when $m_{\mathrm{b}}$ occurs as shown in Fig. 3 and by Eq. (6).

$m_{\mathrm{b}} \propto F_{u}\left(m_{\mathrm{b}}\right)^{-1 / 3}$

Due to the dispersion relationship between the velocity and temperature fluctuations of gravity waves, $F_{T}\left(m_{\mathrm{b}}\right)$ (the spectra of the fractional temperature) is proportional to the corresponding spectra of the horizontal velocity $F_{u}\left(m_{\mathrm{b}}\right)$ (Wang et al., 2000):

$F_{T}\left(m_{\mathrm{b}}\right) \propto F_{u}\left(m_{\mathrm{b}}\right)$.

Thus, $F_{T}\left(m_{\mathrm{b}}\right)$ is also proportional to $m_{\mathrm{b}}^{-3}$ when $m_{\mathrm{b}}$ occurs as described in Eq. (8):

$m_{\mathrm{b}} \propto F_{T}\left(m_{\mathrm{b}}\right)^{-1 / 3}$

The ideal gas law can be written as Eq. (9):

$P=\frac{1}{V} n R T$,

where $P$ is the pressure of the gas, $V$ is the volume of the gas, $n$ is the amount of gas (in moles), $R$ is the gas constant, and $T$ is the absolute temperature of the gas. $n$ can be calculated by Eq. (10):

$n=\frac{m}{\mu m_{u}}$,

where $m$ is the mass of the gas mass, $m_{u}$ is the atomic mass constant, and $\mu$ is the times of average molecular weight to $m_{u}$. Because $\rho=m / V$ (the density of the gas), Eq. (9) can be rewritten as Eq. (11):

$P=\frac{1}{V} \frac{m}{\mu m_{u}} R T=\frac{R}{\mu m_{u}} \rho T$.

When pressure is constant, Eq. (11) can be rewritten as Eq. (12):

$\frac{\partial \rho}{\rho}+\frac{\partial T}{T}=0$.

Equation (12) shows that the fractional density $F_{\rho}\left(m_{\mathrm{b}}\right)$ is proportional to the fractional temperature $F_{T}\left(m_{\mathrm{b}}\right)$ when 
pressure is constant. Thus, $F_{\rho}\left(m_{\mathrm{b}}\right)$ is also proportional to $m_{\mathrm{b}}^{-3}$ when $m_{\mathrm{b}}$ occurs (Eq. 13).

$m_{\mathrm{b}} \propto F_{\rho}\left(m_{\mathrm{b}}\right)^{-1 / 3}$

Thus, $\lambda_{\mathrm{b}}$ (buoyancy wavelength) is proportional to $F_{\rho}\left(\lambda_{\mathrm{b}}\right)^{1 / 3}$ :

$\lambda_{\mathrm{b}} \propto F_{\rho}\left(\lambda_{\mathrm{b}}\right)^{1 / 3}$.

This equation determines the basis of the development of the new algorithm.

\subsection{Algorithm description}

The motion of aerosol in the boundary layer is determined by the background atmosphere (the aerosol particles move with the background atmosphere). Thus, the aerosols and the background share the same fractional fluctuation. $\lambda_{\mathrm{b}}$ is also proportional to $F_{\rho(\text { aerosol) }}\left(\lambda_{b}\right)^{1 / 3}$ (the fractional aerosol density), as illustrated by Eq. (15):

$\lambda_{\mathrm{b}} \propto F_{\rho(\text { aerosol })}\left(\lambda_{\mathrm{b}}\right)^{1 / 3}$.

Equation (15) means that the cubic root of $F_{\rho \text { (aerosol) }}\left(\lambda_{\mathrm{b}}\right)$ reflects $\lambda_{b}$, corresponding to the top of the boundary layer. Equation (15) highlights that the cubic root reflects the relationship of the BLH with fluctuant characteristics of aerosols at the position of BLH. Therefore, the BLH can be determined by capturing the fluctuant characteristic of aerosols. RSCS is proportional to $\rho_{\text {Aerosol }}$ (the density of aerosols) in accordance with the Fernald inversion algorithm of the aerosol lidar equation (Fernald, 1984). The cubic root of the RSCS reflects the characteristics of $\lambda_{b}$ that correspond to $\mathrm{BLH}$; thus the cubic root of the RSCS can be applied to estimate the BLH as described in Eq. (15).

The cubic root gradient method (CRGM), a new algorithm for BLH determination, is thus defined by

$h_{\mathrm{CRGM}}=\min \left[\frac{\partial\left(\mathrm{RSCS}^{1 / 3}\right)}{\partial r}\right]$.

With this new algorithm, the BLH corresponds to the altitude where the cubic root RSCS gradient reaches a minimum. This integrates the impact of gravity waves on the atmospheric structure in determining the BLH.

\section{Evaluation of the new algorithm and comparative analysis with existing methods}

\subsection{During heavily polluted episodes}

Figure $4 \mathrm{~b}$ (similar to Fig. $2 \mathrm{~b}$ ) shows the BLH retrieved by CRGM as a red dotted line. Strong negative peaks were detected in the profiles for each algorithm to define the BLH (Fig. 4b). At 20:00 on 27 July, the BLH retrieved by CRGM
Table 1. Statistical parameters for each lidar retrieval algorithm compared with radiosonde measurements.

\begin{tabular}{lrrrr}
\hline & CRGM & GM & LGM & NGM \\
\hline $\begin{array}{l}\text { Correlation coefficient } \\
\left(R^{2}\right)\end{array}$ & 0.91 & 0.71 & 0.50 & 0.44 \\
RMSE (m) & 142 & 384 & 434 & 498 \\
\hline
\end{tabular}

was $1350 \mathrm{~m}$, in perfect agreement with the actual BLH determined by radiosonde $(1350 \mathrm{~m})$, as opposed to 480 and $1590 \mathrm{~m}$ determined by LGM and NGM, respectively. The diurnal cycles of the BLH retrieved by CRGM presented in Fig. 4a show CRGM's good capture of the unimodal diurnal cycle of the BLH, presenting a peak at 14:00-15:00 and a valley at 07:00-08:00, induced by the thermal activity of the ground. In comparison with CRGM, the BLH determined by LGM and NGM did not present unimodal diurnal cycles. On the other hand, although the GM-retrieved BLH showed a unimodal diurnal cycle, the amplitudes of the valley and peak were lower. Comparing the four-moment radiosonderetrieved BLH (02:00, 08:00, 14:00, 20:00) with the algorithms' results highlights that CRGM presents the least bias, while GM shows an average underestimation of $500-600 \mathrm{~m}$, and LGM and NGM result in an average overestimation of 400-500 m. To enrich our analysis, a comparison of CRGM with the other most frequently employed methods for BLH retrieval, such as the ideal curve fit (Steyn et al., 1999) and wavelet method (Davis et al., 2000), is provided in the Supplement (Figs. S4-S6). The result illustrates that fitting curve and wavelet methods also significantly underestimate BLH by approximately 600 and $800 \mathrm{~m}$ in maximum, respectively, during heavily polluted episodes in line with several other previous studies (Sawyer and Li, 2013; Wang et al., 2012; Su et al., 2017).

In order to further compare the performance of CRGM with the current algorithms in heavily polluted episodes, the period of daily $\mathrm{PM}_{2.5}$ concentrations exceeding the Grade II National Ambient Air Quality Standards (light pollution, GB3095-2012, $75 \mu \mathrm{g} \mathrm{m}^{-3}, 24 \mathrm{~h}$ average) is particularly analyzed (in total 24 days). Radiosonde data of four corresponding times are used to evaluate retrieval algorithm results. Cloudy and rainy weather conditions are ignored to prevent increase of bias during the BLH retrieval process. There are 89 available samples for each algorithm. Figure 5 presents the discrepancies between the retrieval algorithm results and the radiosonde-detected BLH. Although the retrieval errors are limited in CRGM, it shows slightly symmetric height bias distribution of about $200 \mathrm{~m}$. In contrast, the LGM and NGM retrievals significantly overestimate the BLH, with a height bias range of $60-1110 \mathrm{~m}$, exceeding $300 \mathrm{~m}$ for more than $85 \%$ of the measurements (orange region in Fig. 5). The GM algorithm underestimates the BLH by $30-1140 \mathrm{~m}$, with an underestimation of more than $300 \mathrm{~m}$ occurring $70 \%$ of the 

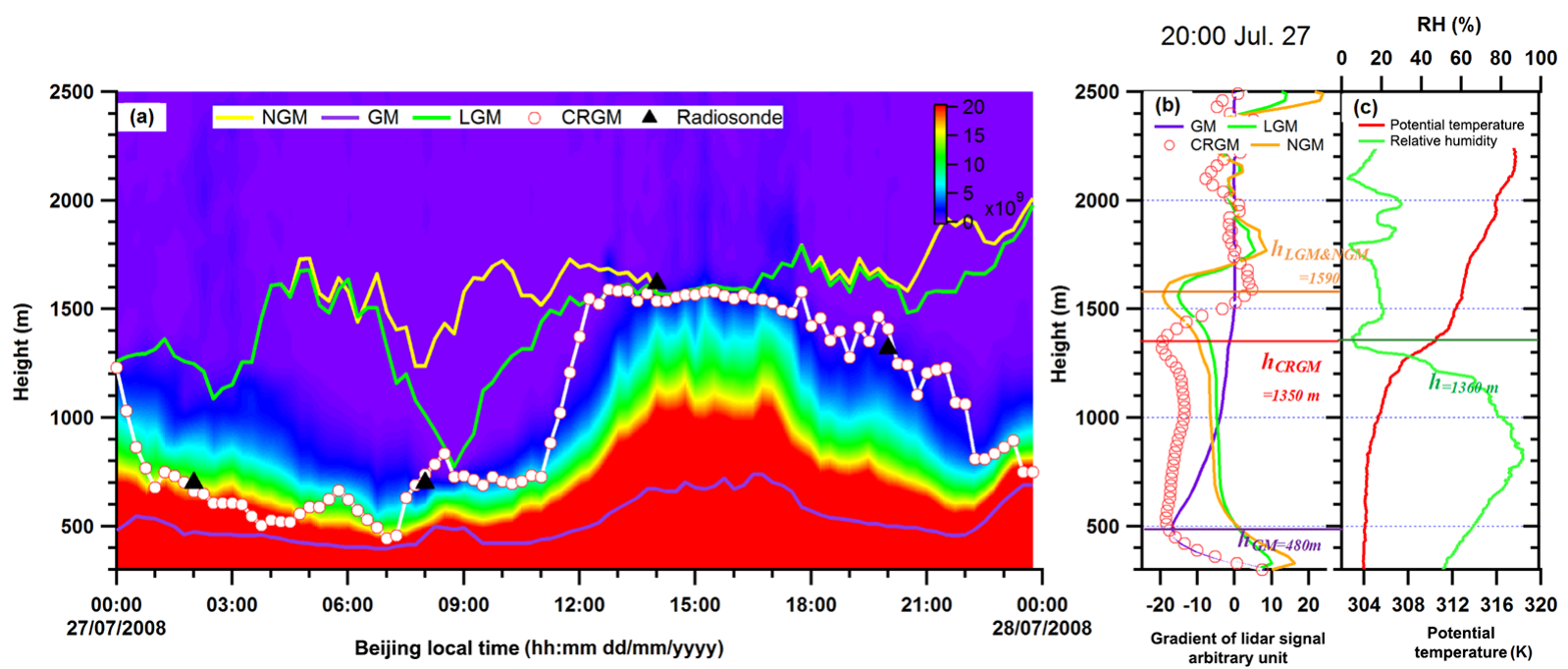

Figure 4. (a) Same as Fig. 2a but with the addition of the diurnal BLH retrieved by CRGM as a white line with red outline and white circles. (b) Same as Fig. $2 b$ but with the addition of the CRGM profile as a red dotted line. (c) Same as Fig. 2c.

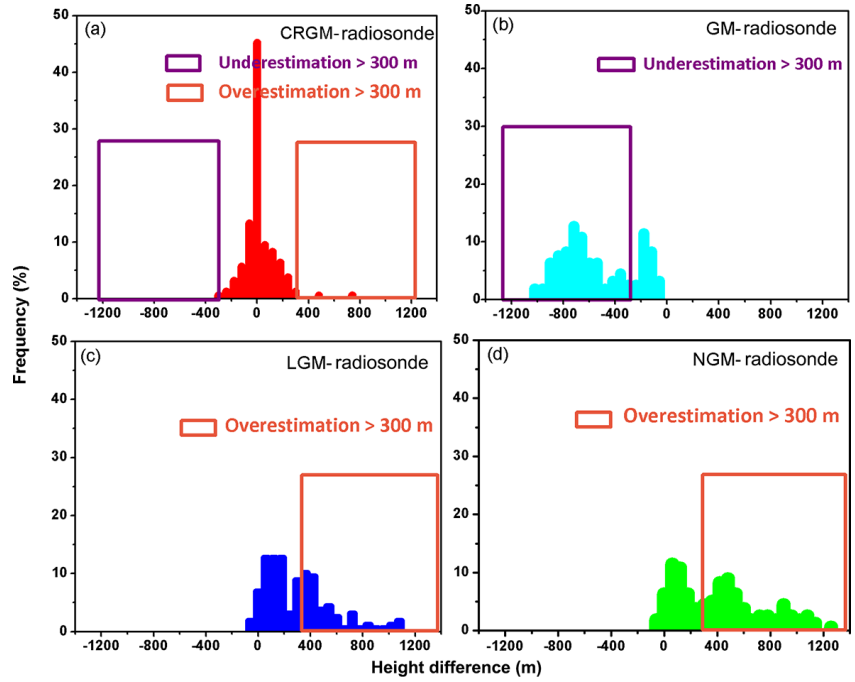

Figure 5. Histograms of the differences in BLH detected by radiosonde and by CRGM, NGM, LGM, and GM. The $x$ axis is the height difference $(\mathrm{m})$ between the retrieved BLH and that from radiosonde, and the $y$ axis is the frequency of occurrence (\%). The orange and purple regions highlight height differences of more than $\pm 300 \mathrm{~m}$.

time (purple region). CRGM accurately reproduces the fluctuations of the BLH for these samples and shows the weakest bias in the BLH retrieval (Table 1). The CRGM algorithm also shows the best correlation, with a coefficient of 0.91 , and the weakest root mean square error (RMSE) $(142 \mathrm{~m})$. The correlation coefficient is enhanced by at least 0.44 , and the RMSE is reduced by more than $400 \mathrm{~m}$ in comparison with corresponding results of the other three algorithms. However, minor discrepancies still subsist between CRGM and radiosonde for some possible reasons: (1) the locations of the lidar and radiosonde measurements are $24 \mathrm{~km}$ apart, which may induce slight BLH bias, and (2) the potential temperature profile observed by radiosonde and the aerosol concentration profile observed by lidar might be inconsistent as previously reported by Hennemuth and Lammert (2006). Nevertheless, CRGM shows the best performance in determining the BLH during pollution episodes induced by stagnant air.

\subsection{Under conditions of clean atmosphere}

To investigate the performance of the algorithms under clean meteorological conditions, a comparison between the new and current algorithms is performed on 9 August 2008 with low $\mathrm{PM}_{2.5}$ concentrations $\left(\sim 81 \mu \mathrm{g} \mathrm{m}^{-3}\right)$. Figure 6a shows the boundary layer evolution in terms of the time-height cross-sectional observation of RSCS in the $532 \mathrm{~nm}$ channel collected on 9 August 2008. Similar to the result noticed on 27 July, the BLH presents an obvious diurnal cycle, with a valley at 08:00-09:00 and peak at 14:00-15:00, due to the thermal diurnal cycle of the ground surface. In contrast to $27 \mathrm{July}$, the boundary increases more quickly at a rate of about $240 \mathrm{~m} \mathrm{~h}^{-1}$ from 09:00 to 15:00, corresponding to 1.7 times the rate on the polluted day. The maximum height of the boundary layer of approximately $1800 \mathrm{~m}$ is reached at 15:00, $\sim 500 \mathrm{~m}$ higher than the height on the polluted day. Such a difference between the BLH on polluted and clean days might be explained by the fact that heavy aerosol loading affects radiative forcing and lowers the BLH on polluted days (Quan et al., 2013).

Figure $6 \mathrm{~b}$ shows strong negative peaks in the profiles for each algorithm to determine the BLH. At 14:00 on 9 August the retrieved BLH for all algorithms is $1680 \mathrm{~m}$, in perfect agreement with the actual BLH determined by radiosonde 

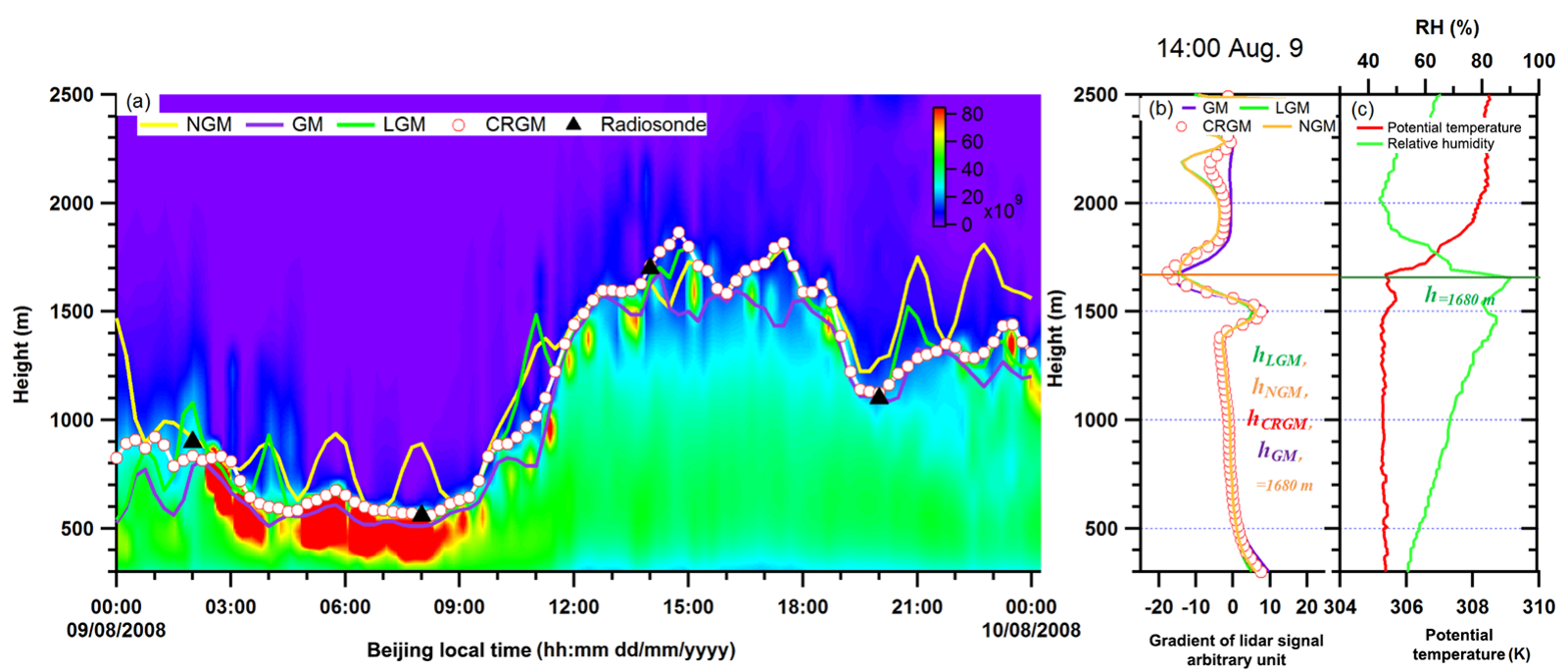

Figure 6. (a) Same as Fig. 4a but for 9 August. (b) Same as Fig. 4b but for 14:00 on 9 August. (c) Same as Fig. 4c but for 14:00 on 9 August.

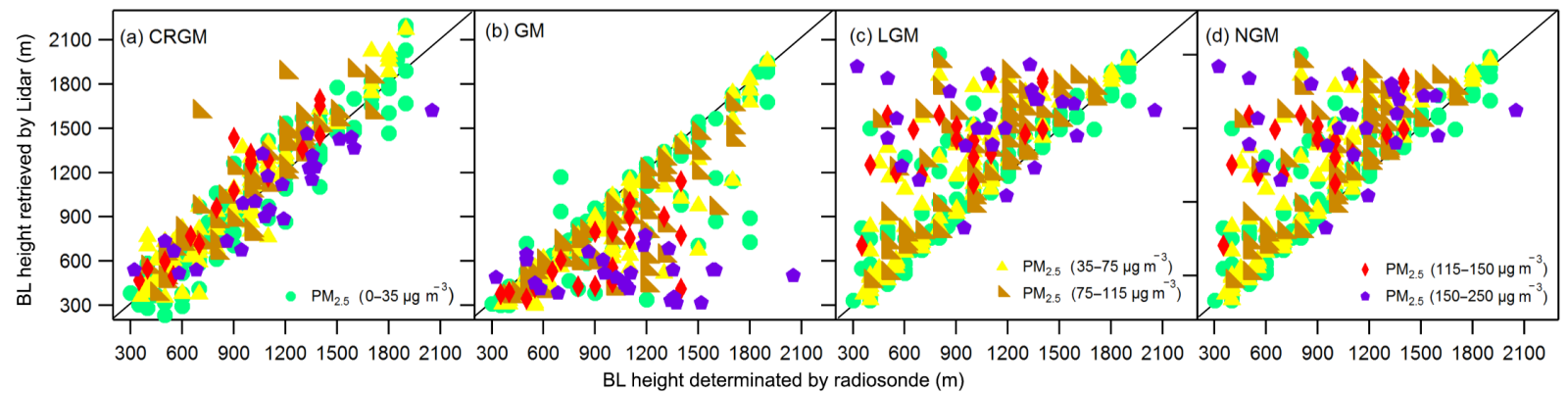

Figure 7. Comparison of $H_{\mathrm{CRGM}}, H_{\mathrm{GM}}, H_{\mathrm{LGM}}$, and $H_{\mathrm{NGM}}$ with the $\mathrm{BLH}$ retrieved from radiosonde measurements. The $x$ axis shows the radiosonde retrieval, and the $y$ axis is the lidar retrieval using the different algorithms. The solid line indicates $y=x$. (a) CRGM, (b) GM, (c) LGM, (d) NGM. Different marks represent the comparisons under different pollution conditions ( $\mathrm{PM}_{2.5}$ concentrations). The comparisons under $\mathrm{PM}_{2.5}$ concentrations less than $35,35-75,75-115,115-150$, and 150-250 $\mu \mathrm{g} \mathrm{m}^{-3}$ are shown as green circles, yellow triangles, brown triangles, red diamonds, and purple hexagons, respectively.

$(1680 \mathrm{~m})$. All diurnal cycle results converge at 14:00 on 9 August, demonstrating that all retrieval algorithms capture the overall diurnal cycle of the actual BLH. Comparison of CRGM with existing ideal curve fit and wavelet methods also confirms such performance (Fig. S7). Such good performance of all the algorithms under clean meteorological conditions is a result of the homogenous vertical distribution of aerosols, since under clean conditions, mixing of the aerosols by strong thermal convection is more sufficient due to weak pollutant loading. In addition, there is no obvious large negative gradient peak to disturb the determination of the BLH.

\subsection{At various pollution levels}

Under various air pollution conditions (all pollution levels), a total of 298 radiosondes measurements are analyzed to estimate the BLH with comparison to retrieval algorithms. Cases of nocturnal BLH below the useful lidar signal (before
Table 2. Root mean square error (RMSE) for each lidar retrieval method compared with radiosonde measurements and sample size in each comparison level.

\begin{tabular}{lrrrrr}
\hline $\begin{array}{l}\mathrm{PM}_{2.5} \\
\left(\mu \mathrm{g} \mathrm{m}^{-3}\right)\end{array}$ & $\begin{array}{r}\text { CRGM } \\
(\mathrm{m})\end{array}$ & $\begin{array}{r}\text { GM } \\
(\mathrm{m})\end{array}$ & $\begin{array}{r}\text { LGM } \\
(\mathrm{m})\end{array}$ & $\begin{array}{r}\text { NGM } \\
(\mathrm{m})\end{array}$ & Samples \\
\hline $0-35$ & 124 & 124 & 137 & 129 & 114 \\
$35-75$ & 123 & 133 & 238 & 227 & 88 \\
$75-115$ & 135 & 213 & 320 & 418 & 53 \\
$115-150$ & 154 & 310 & 346 & 434 & 19 \\
$150-250$ & 137 & 629 & 636 & 643 & 24 \\
\hline
\end{tabular}

the overlap reaches 1) or thin cumulus cloud formations at the upper boundary layer (resulting in large error in the retrieval) are neglected. The cloud and rain detection follows the methods employed by the Asian Dust and Aerosol Lidar Observation Network (AD-net) in East Asia, supported 
by the World Meteorological Organization (WMO) Global Atmosphere Watch (GAW) program. Rain was detected by color ratio $\left(\gamma^{\prime}\right.$, the ratio of $\beta_{1064}^{\prime}$ to $\left.\beta_{532}^{\prime}\right)$ to distinguish rainy and clear (no rain) regions, in which $\beta_{1064}^{\prime}$ and $\beta_{532}^{\prime}$ present the attenuated backscatter coefficient at 1064 and $532 \mathrm{~nm}$, respectively. Large droplets have a large $\gamma^{\prime}$ value, so once $\gamma^{\prime}$ exceeds a threshold (1.1) over a certain vertical internal in the lower atmosphere, the profile is classified as a rain profile. Cloud base height is determined by the vertical gradient of $\beta_{1064}^{\prime}$ and the peak value of $\beta_{1064}^{\prime}$ between the cloud base and the apparent cloud top. A detailed description of the method is provided by Shimizu et al. (2016). The 298 samples are categorized into five groups according to the corresponding hourly $\mathrm{PM}_{2.5}$ concentration. We compare retrieved BLH by the algorithms from lidar with the radiosonde results in each group. As illustrated in Fig. 7, the retrieval results of CRGM are close to the $1: 1$ line, while the GM, LGM, and NGM present large biases. The GM results are generally below the $1: 1$ line, highlighting an underestimation of the BLH. LGM and NGM in general overestimate the BLH in all five comparison groups. The RMSE ranges over 124-137 $\mathrm{m}$ for CRGM, as opposed to $124-642 \mathrm{~m}$ for the other three algorithms. Furthermore, the RMSE of the three existing algorithms increases with the $\mathrm{PM}_{2.5}$ concentrations (Table 2). For the GM algorithm, the RMSE increases from 124 to $629 \mathrm{~m}$ with an increase of $\mathrm{PM}_{2.5}$ concentration from 35 to $250 \mu \mathrm{g} \mathrm{m}^{-3}$. Similarly, the RMSE of LGM and NGM increases from $\sim 130$ to $540 \mathrm{~m}$ with a $\mathrm{PM}_{2.5}$ concentration increase from 35 to $250 \mu \mathrm{g} \mathrm{m}^{-3}$. High aerosol loading is therefore always associated with higher RMSE. In contrast, the RMSE of CRGM remains relatively constant with the changes of air pollution level. These results perfectly corroborate the findings discussed in Sect. 4.1 and 4.2. It is clear that existing retrieval algorithms are only suitable to the aerosol profiles similar to the "textbook" boundary layer development, while CRGM appears to be a robust technique for BLH determination by lidar.

\section{Conclusions and environmental implication}

Lidar is an appropriate instrument with which to determine the boundary layer height with high temporal and vertical resolution. In this paper, an intensive lidar observation campaign was conducted in Beijing to thoroughly evaluate the limitations of the current method for boundary layer height determination and develop an algorithm suitable to all pollution conditions. Incontestably, current commonly employed retrieval algorithms (first gradient method, logarithm gradient method, and normalized gradient method) are unable to determine the boundary layer height during heavily polluted episodes due to inhomogeneous vertical distribution of aerosols under stable meteorological conditions associated with the impact of vertically propagating gravity waves on the tropospheric structure. The gradient algorithm critically underestimates the boundary layer height by $30-1140 \mathrm{~m}$, with an underestimation higher than $300 \mathrm{~m}$ occurring $70 \%$ of the time. The logarithm and normalized gradient methods overestimate the boundary layer height, exceeding $300 \mathrm{~m}$ more than $85 \%$ of the time.

The newly developed method (the cubic root gradient) considers the linear instability theory of gravity waves to determine the boundary layer height by capturing the vertical movement of aerosol at the transition between waves and turbulence. As a result, the cubic root gradient method describes the fluctuation of the boundary layer with the best correlation $\left(R^{2}=0.91\right)$ and the weakest RMSE $(142 \mathrm{~m})$ under various atmospheric pollution conditions. In comparison with current gradient methods, the new technique reduces the RMSE by $400 \mathrm{~m}$ minimum under all pollution conditions. The RMSE of existing retrieval algorithms typically varies with aerosol loading (high RMSE is always associated with heavy aerosol loading, and weak RMSE correlates with weak aerosol loading), while the RMSE of the new method remains almost constant with the changes of air pollution levels. The cubic root gradient method appears therefore to be a robust technique for boundary layer height determination from lidar.

In terms of environmental implication, such innovation would technically contribute to improving the accuracy of regionally spatiotemporal distribution models and forecasts of aerosol loadings for an effective pollution control measure, in particular over a number of megacities in China, since accurately determining the boundary layer is one of the important factors of uncertainties and bias reduction for reasonable air pollution modeling and forecasts. However, further development and expansion of lidar observation system are needed notably under cloudy and rainy conditions in order to provide a greater benefit to pollution control management.

Data availability. Contact Ting Yang (tingyang@mail.iap.ac.cn) for data requests.

\section{The Supplement related to this article is available online at doi:10.5194/acp-17-6215-2017-supplement.}

Competing interests. The authors declare that they have no conflict of interest.

Acknowledgements. This work was supported by the Natural National Science Foundation of China (NSFC) (41305115, 41225019), Program 973 (2014CB447900), the Commonweal Project of the Ministry of Environmental Protection (201409001), and Program 863 (2014AA06AA06A512). Ting Yang is grateful for the invaluable emotional support received from her family over the years to overcome all the periods of darkness, and the endless happiness and courage received from her baby daughter. 
Edited by: F. Yu

Reviewed by: three anonymous referees

\section{References}

Ansari, A. S., and Pandis, S. N.: Response of inorganic PM to precursor concentrations, Environ. Sci. Technol., 32, 2706-2714, 1998.

Baars, H., Ansmann, A., Engelmann, R., and Althausen, D.: Continuous monitoring of the boundary-layer top with lidar, Atmos. Chem. Phys., 8, 7281-7296, doi:10.5194/acp-8-7281-2008, 2008.

Boers, R. and Melfi, S. H.: Cold air outbreak during MASEX: Lidar observations and boundary-layer model test, Bound.-Lay. Meteorol., 39, 41-51, doi:10.1007/bf00121864, 1987.

Chan, C. K. and Yao, X.: Air pollution in mega cities in China, Atmos. Environ., 42, 1-42, doi:10.1016/j.atmosenv.2007.09.003, 2008.

Dabberdt, W. F., Carroll, M. A., Baumgardner, D., Carmichael, G., Cohen, R., Dye, T., Ellis, J., Grell, G., Grimmond, S., Hanna, S., Irwin, J., Lamb, B., Madronich, S., McQueen, J., Meagher, J., Odman, T., Pleim, J., Schmid, H. P., and Westphal, D. L.: Meteorological Research Needs for Improved Air Quality Forecasting: Report of the 11th Prospectus Development Team of the U.S. Weather Research Program*, B. Am. Meteorol. Soc., 85, 563586, doi:10.1175/bams-85-4-563, 2004.

Dandou, A., Tombrou, M., Schäfer, K., Emeis, S., Protonotariou, A. P., Bossioli, E., Soulakellis, N., and Suppan, P.: A Comparison Between Modelled and Measured Mixing-Layer Height Over Munich, Bound-Lay. Meteorol., 131, 425-440, doi:10.1007/s10546-009-9373-7, 2009.

Davis, K. J., Gamage, N., Hagelberg, C. R., Kiemle, C., Lenschow, D. H., and Sullivan, P. P.: An Objective Method for Deriving Atmospheric Structure from Airborne Lidar Observations, J. Atmos. Oceanic Technol., 17, 1455-1468, doi:10.1175/15200426(2000)017<1455:aomfda>2.0.co;2, 2000.

Dewan, E. M. and Good, R. E.: Saturation and the "universal" spectrum for vertical profiles of horizontal scalar winds in the atmosphere, J. Geophys. Res.-Atmos., 91, 2742-2748, 1986.

Dupont, E., Pelon, J., and Flamant, C.: Study of the moist Convective Boundary Layer structure by backscattering lidar, Bound.Lay. Meteorol., 69, 1-25, doi:10.1007/bf00713292, 1994.

Emeis, S., Jahn, C., Munkel, C., Munsterer, C., and Schafer, K.: Multiple atmospheric layering and mixing-layer height in he Inn valley observed by remote sensing, Meteorol. Z., 16, 415-424, 2007.

Fernald, F. G.: Analysis of atmospheric lidar observations - Some comments, Appl. Opt., 23, 652-653, 1984.

Flamant, C., Pelon, J., Flamant, P., and Durand, P.: Lidar Determination Of The Entrainment Zone Thickness At The Top Of The Unstable Marine Atmospheric Boundary Layer, Bound.-Lay. Meteorol., 83, 247-284, doi:10.1023/a:1000258318944, 1997.

Fritts, D. C. and Alexander, M. J.: Gravity wave dynamics and effects in the middle atmosphere, Rev. Geophys., 41, 1003-1066, doi:10.1029/2001rg000106, 2003.

Gardner, C. S.: Testing theories of atmospheric gravity wave saturation and dissipation, J. Atmos. Terr. Phys., 58, 1575-1589, 1996.
Gibert, F., Arnault, N., Cuesta, J., Plougonven, R., and Flamant, P. H.: Internal gravity waves convectively forced in the atmospheric residual layer during the morning transition, Q. J. Roy. Meteor. Soc., 137, 1610-1624, doi:10.1002/qj.836, 2011.

Gong, S., Yang, G., Xu, J., Wang, J., Guan, S., Gong, W., and $\mathrm{Fu}, \mathrm{J}$.: Statistical characteristics of atmospheric gravity wave in the mesopause region observed with a sodium lidar at Beijing, China, J. Atmos. Sol.-Terr. Phy., 97, 143-151, doi:10.1016/j.jastp.2013.03.005, 2013.

Hayden, K. L., Anlauf, K. G., Hoff, R. M., Strapp, J. W., Bottenheim, J. W., Wiebe, H. A., Froude, F. A., Martin, J. B., Steyn, D. G., and McKendry, I. G.: The vertical chemical and meteorological structure of the boundary layer in the Lower Fraser Valley during Pacific '93, Atmos. Environ., 31, 20892105, doi:10.1016/S1352-2310(96)00300-7, 1997.

He, Q. S., Mao, J. T., Chen, J. Y., and Hu, Y. Y.: Observational and modeling studies of urban atmospheric boundary-layer height and its evolution mechanisms, Atmos. Environ., 40, 1064-1077, doi:10.1016/j.atmosenv.2005.11.016, 2006.

Hennemuth, B. and Lammert, A.: Determination of the Atmospheric Boundary Layer Height from Radiosonde and Lidar Backscatter, Bound.-Lay. Meteorol., 120, 181-200, doi:10.1007/s10546-005-9035-3, 2006.

Hooper, W. P. and Eloranta, E. W.: Lidar measurements of wind in the planetary borendary layer: the method, accuracy and results from joint measurement with radiosonde and kytoon, Am. Meteorol. Soc., 25, 990-1001, 1986.

Melfi, S., Spinhirne, J., Chou, S., and Palm, S.: Lidar observations of vertically organized convection in the planetary boundary layer over the ocean, J. Clim. Appl. Meteorol., 24, 806-821, 1985.

Pal, S., Behrendt, A., and Wulfmeyer, V.: Elastic-backscatter-lidarbased characterization of the convective boundary layer and investigation of related statistics, Ann. Geophys., 28, 825-847, 2010.

Park, O. H., Seo, S. J., and Lee, S. H.: Laboratory Simulation Of Vertical Plume Dispersion Within A Convective Boundary Layer, Bound.-Lay. Meteorol., 99, 159-169, doi:10.1023/a:1018731205971, 2001.

Piironen, A. K. and Eloranta, E. W.: Convective boundary layer mean depths and cloud geometrical properties obtained from volume imaging lidar data, J. Geophys. Res.-Atmos., 100, 2556925576, doi:10.1029/94jd02604, 1995.

Quan, J., Gao, Y., Zhang, Q., Tie, X., Cao, J., Han, S., Meng, J., Chen, P., and Zhao, D.: Evolution of planetary boundary layer under different weather conditions, and its impact on aerosol concentrations, Particuology, 11, 34-40, doi:10.1016/j.partic.2012.04.005, 2013.

Sawyer, V. and Li, Z.: Detection, variations and intercomparison of the planetary boundary layer depth from radiosonde, lidar and infrared spectrometer, Atmos. Environ., 79, 518-528, doi:10.1016/j.atmosenv.2013.07.019, 2013.

Seibert, P., Beyrich, F., Gryning, S.-E., Joffre, S., Rasmussen, A., and Tercier, P.: Review and intercomparison of operational methods for the determination of the mixing height, Atmos. Environ., 34, 1001-1027, doi:10.1016/S1352-2310(99)00349-0, 2000.

Senff, C., Bösenberg, J., Peters, G., and Schaberl, T.: Remote sensing of turbulent ozone fluxes and the ozone budget in the convec- 
tive boundary layer with DIAL and radar-RASS: a case study, Contributions Atmos. Phys., 69, 161-176, 1996.

Shimizu, A., Nishizawa, T., Jin, Y., Kim, S.-W., Wang, Z., Batdorj, D., and Sugimoto, N.: Evolution of a lidar network for tropospheric aerosol detection in East Asia, OPTICE, 56, 031219031219, doi:10.1117/1.OE.56.3.031219, 2016.

Sicard, M., Pérez, C., Rocadenbosch, F., Baldasano, J. M., and García-Vizcaino, D.: Mixed-Layer Depth Determination in the Barcelona Coastal Area From Regular Lidar Measurements: Methods, Results and Limitations, Bound.-Lay. Meteorol., 119, 135-157, doi:10.1007/s10546-005-9005-9, 2006.

Stettler, M. and Hoyningen-Huene, W.: On the relation between haze layer and air mass aerosol at an urban location - Case studies, Atmos. Res., 40, 1-18, doi:10.1016/0169-8095(95)00029-1, 1996.

Steyn, D. G., Baldi, M., and Hoff, R. M.: The Detection of Mixed Layer Depth and Entrainment Zone Thickness from Lidar Backscatter Profiles, J. Atmos. Ocean. Technol., 16, 953-959, 1999.

Stull, R. B.: An introduction to boundary layer meteorology, Springer, 1988.

Su, T., Li, J., Li, C., Xiang, P., Lau, A. K.-H., Guo, J., Yang, D., and Miao, Y.: An intercomparison of long-term planetary boundary layer heights retrieved from CALIPSO, ground-based lidar and radiosonde measurements over Hong Kong, J. Geophys. Res.Atmos., 122, 3929-3943, doi:10.1002/2016jd025937, 2017.

Sugimoto, N., Matsui, I., Shimizu, A., Uno, I., Asai, K., Endoh, T., and Nakajima, T.: Observation of dust and anthropogenic aerosol plumes in the Northwest Pacific with a two-wavelength polarization lidar on board the research vessel Mirai, Geophys. Res. Lett., 29, 1901, doi:10.1029/2002gl015112, 2002.
Sun, Y., Jiang, Q., Wang, Z., Fu, P., Li, J., Yang, T., and Yin, Y.: Investigation of the sources and evolution processes of severe haze pollution in Beijing in January 2013, J. Geophys. Res.-Atmos., 119, 4380-4398, doi:10.1002/2014jd021641, 2014.

Tie, X., Madronich, S., Li, G., Ying, Z., Zhang, R., Garcia, A. R., Lee-Taylor, J., and Liu, Y.: Characterizations of chemical oxidants in Mexico City: A regional chemical dynamical model (WRF-Chem) study, Atmos. Environ., 41, 1989-2008, doi:10.1016/j.atmosenv.2006.10.053, 2007.

Wang, D. Y., Ward, W. E., Solheim, B. H., and Shepherd, G. G.: Wavenumber spectra of horizontal wind and temperature measured with WINDII, Part II: diffusive effect on spectral formation, J. Atmos. Sol.-Terr. Phy., 62, 981-991, doi:10.1016/S13646826(00)00065-1, 2000.

Wang, Z., Cao, X., Zhang, L., Notholt, J., Zhou, B., Liu, R., and Zhang, B.: Lidar measurement of planetary boundary layer height and comparison with microwave profiling radiometer observation, Atmos. Meas. Tech., 5, 1965-1972, doi:10.5194/amt5-1965-2012, 2012.

Yang, T., Wang, Z., Zhang, B., Wang, X., Wang, W., Gbauidi, A., and Gong, Y.: Evaluation of the effect of air pollution control during the Beijing 2008 Olympic Games using Lidar data, Chin. Sci Bull., 55, 1311-1316, doi:10.1007/s11434-010-0081-y, 2010. 